\title{
Efikasi Diri dan Stres Kerja Pemandu Lalu Lintas Udara Bandara
}

\author{
Hary Yon Witjaksono \\ Nur Pratiwi Noviati \\ Program Studi Psikologi, Fakultas Psikologi dan Ilmu Sosial Budaya \\ Universitas Islam Indonesia, Yogyakarta
}

\begin{abstract}
This study aims to determine the relationship between self-efficacy and job stress among Air Traffic Controllers in one of airport in Indonesia. The hypothesis of this study is that there is a negative relationship between self-efficacy and job stress among Air Traffic Controller. The subjects in this study involved 70 Air Traffic Controllers, age ranged from 21 to 50 years, 50 males and 20 females. Self-efficacy scales with 18 items $(\alpha=0.888)$, and job stress scales with 24 items $(\alpha=0899)$ was used in this study. Pearson product moment correlation with SPSS was performed for data analysis. The result indicated that there was a negative correlation between self-efficacy and job stress $(r=-0.634, \mathrm{p}=0.000(p<0.05))$. Therefore, research hypothesis was supported.
\end{abstract}

Keywords: air traffic controller, self efficacy, work stress

\begin{abstract}
Abstrak. Penelitian ini bertujuan untuk menguji hubungan antara efikasi diri dan stres kerja pada PLLU di salah satu bandara di Indonesia. Hipotesis penelitian ini adalah terdapat hubungan negatif antara efikasi diri dan stress kerja. Subjek penelitian ini terdiri dari 70 orang PLLU yang memiliki rentang umur 21 tahun sampai dengan 50 tahun, terdiri dari 50 orang laki-laki dan 20 orang perempuan. Alat ukur yang digunakan adalah skala efikasi diri yang terdiri dari 18 aitem $(\alpha=0.888)$ dan skala stress kerja yang terdiri dari 24 aitem $(\alpha=0899)$. Uji korelasi Person menunjukkan korelasi sebesar $r=-0.634$ dan $p=0.000(p<0.05)$. Hasilnya menunjukkan bahwa terdapat korelasi negative antara efikasi diri dan stress kerja, dan demikina hipotesis penelitian ini diterima.
\end{abstract}

kata kunci: efikasi diri, pemandu lalu lintas udara, stres kerja

Di Indonesia saat ini pertumbuhan transportasi udara dapat dikatakan berkembang pesat. Pada tahun 2016 terdapat 61 maskapai penerbangan niaga berjadwal yaitu maskapai yang memiliki jadwal penerbangan tetap setiap harinya dan tidak berjadwal yang tidak memiliki jadwal terbang tetap, serta maskapai yang terdaftar serta penerbangan kargo (Pamudji, 2016).
Transportasi udara yang ada saat ini membutuhkan sektor pendukung baik dari sisi fasilitas dan sumber daya manusianya. Salah satu sumber daya manusia yang harus hadir dalam menunjang transportasi udara adalah Air Traffic Controller atau dalam bahasa Indonesia lebih dikenal dengan Pemandu Lalu Lintas Udara (PLLU). Tugas PLLU secara umum bertugas untuk mengatur

Korespondensi: Hary Yon Witjaksono. Email: haryyonw@gmail.com 
pergerakan lalu lintas pesawat.

Seorang PLLU harus menjalani pendidikan khusus dan seleksi yang ketat. Ketatnya kriteria untuk menjadi seorang PLLU disebabkan tugas dan tanggung jawabnya yang sangat penting dalam mengatur ruang lalu lintas udara. Sedikit kesalahan dari PLLU dalam mengatur lalu lintas udara bisa menyebabkan akibat yang fatal yaitu kecelakaan. Salah satu kecelakaan pesawat yang melibatkan PLLU terjadi pada penerbangan Bashkirian pada 2002 yang mengalami tabrakan saat mengudara dengan korban tewas 71 orang (Bundesstelle fur Flugunfalluntersuchung, 2004).

Transportasi udara merupakan salah satu moda transportasi paling aman dibandingkan yang lainnya. Seorang akan memiliki kemungkinan celaka di jalan raya lebih besar daripada dengan moda transportasi udara. Seorang akan memiliki kemungkinan mengalami kecelakaan sebanyak 1 kali di udara dalam setiap 7178 melakukan perjalanan dengan pesawat. Keamanan moda transportasi udara ditunjang dengan dukungan dari teknologi yang semakin canggih dan sumber daya manusia yang dituntut sempurna. Transportasi udara menjadi pilihan yang paling diminati masyarakat diiringi dengan perkembangan bisnis yang menjanjikan bagi segelintir pengusaha. Globalisasi yang terjadi saat ini membuat banyak pengusaha memiliki kemudahan untuk mendapatkan peminjaman utang di luar negri untuk modal mendirikan maskapai penerbangan. Kemudahan dalam mendapatkan modal membuat jumlah pesawat yang terbang di langit Indonesia semakin banyak. Arus lalu lintas udara di Indonesia mulai padat terutama di daerah-daerah wisata dan bisnis.

Kepadatan lalu lintas udara menuntut para pekerja yang terlibat dalam dunia penerbangan bekerja lebih. PLLU, Pilot dan Ground Staff juga semakin dituntut tahan dalam tekanan kerja. PLLUdituntut untuk mampu melakukan pekerjaan dengan sempurna tanpa cacat sedikitpun. PLLU bekerja dengan tugas pokok pelayanan lalu lintas udara berdasarkan Peraturan Keselamatan Penerbangan Sipil (PKPS) bagian 170 tentang lalu lintas udara. PLLU secara umum bertugas untuk mengatur pergerakan pesawat yang sedang mengudara, akan terbang maupun mendarat. Peraturan Keselamatan Penerbangan Sipil (PKPS) bagian 170 menjelaskan lebih rinci bahwa tugas PLLU antara lain adalah untuk mencegah tabrakan pesawat, mempercepat dan mempertahankan pergerakan pesawat, memberi saran dan informasi yang berguna bagi keselamatan dan efisiensi lalu lintas serta memberitahukan kepada pihak berwenang terhadap pencarian atau evakuasi terhadap kecelakaan udara yang terjadi.

Di Indonesia para PLLU bekerja di bawah Perum LPPNPI atau yang lebih dikenal dengan AirNav. AirNav adalah salah satu BUMN yang 
dibentuk khusus oleh Kementrian Perhubungan untuk bertanggung jawab terhadap kelancaran lalu lintas udara di Indonesia. Semakin padatnya lalu lintas udara dan terbatasnya jumlah PLLU yang ada saat ini membuat banyak para PLLU yang mengalami tekanan dan dapat menyebabkan stres saat bekerja maupun setelah selesai melakukan aktifitas pekerjaannya (Taufik, 2013).

Seorang PLLU idealnya harus memiliki stres kerja yang rendah. Resiko pekerjaan yang tinggi dan melibatkan nyawa orang banyak menjadi beban dan tanggung jawab tersendiri bagi seorang PLLU. Pada ruang lingkup dunia penerbangan internasional dan nasional kecelakaan yang terjadi akibat kesalahan PLLU sudah beberapa kali terjadi. Salah satu kejadian yang pernah terjadi dan diduga melibatkan pengatur lalu lintas sebagai penyebabnya adalah kecelakaan GA 152 jenis Airbus A300B4-200 yang jatuh pada tanggal 26 September 1997 sekitar pukul 13.30 WIB di kawasan perladangan warga di Desa Buah Nabar Kecamatan Sibolangit Kabupaten Deli Serdang, sekitar 50 kilometer dari Medan yang mengakibatkan 222 penumpang dan 12 awak pesawat tewas. Kejadian tersebut terjadi dikarenakan PLLU gagal memandu pesawat GA 152 yang diterbangkan oleh Pilot Hance Rahmowiyogo menghindari kabut asap dan menabrak wilayah perbukitan sesaat sebelum mendarat di Bandara Polonia Medan (Gunawan, 2015). Kejadian tersebut menunjukan kritisnya pengaruh pekerjaan seorang PLLU dalam dunia penerbangan. PLLU harus mampu mengatur pergerakan pesawat secara cepat dan tepat. Pilot membutuhkan bantuan PLLU untuk berkoordinasi mengenai keadaan di udara dan di darat. Keputusan pilot untuk menyalakan mesin, merubah ketinggian dan kecepatan pesawat juga harus mendapatkan izin dari PLLU. Pesawat yang akan terbang, mengudara dan mendarat membutuhkan izin dari PLLU untuk menghindari kejadian yang tidak diinginkan dan keteraturan jadwal penerbangan.

Menjadi PLLU tidak mudah karena harus melalui pendidikan khusus yang ketat. Ketatnya pendidikan PLLU ditujukan untuk menciptakan sumber daya manusia yang berkompeten dan disiplin dalam bekerja. Seorang PLLU harus disiplin dan memiliki fokus yang baik. PLLU bekerja dengan cara berkomunikasi melalui jaringan komunikasi khusus dibantu dengan sistem instrumen yang ada di ruang kerja. Instrumen yang membantu kerja PLLU merupakan alat-alat yang digunakan untuk mengetahui koordinat pesawat, arah angin, pergerakan pesawat dan informasi cuaca. Keadaan lalu lintas udara di Indonesia sendiri yang padat dan sistem radar yang ada juga dapat dikatakan sudah tertinggal dan sering mengalami kerusakan. Sistem radar yang dimiliki saat ini juga sudah tertinggal dengan negara tetangga seperti Singapura dan Malaysia. Insiden yang hampir terjadi salah 
satunya adalah pada saat radar Bandara Soekarno Hatta yang sempat mati membuat pesawat Lion Air hampir bertabrakan di udara. Kondisi tersebut dapat menjadi potensi stres kerja dan menambah tingkat kesulitas tugas bagi seorang PLLU karena harus memandu dengan peralatan seadanya, dimana sewaktu waktu dapat menjadi ancaman dan mengakibatkan kejadian fatal (Kusumadewi \& Galih, 2012).

Woolfolk (Mangkunegara, 2009) berpendapat efikasi diri merupakan penilaian terhadap diri sendiri atau tingkat keyakinan individu mengenai seberapa besar kemampuan dalam menyelesaikan suatu pekerjaan dengan mencapai hasil tertentu. Seorang yang tidak berhasil mengatasi stres cenderung akan menghindar atau menarik diri secara psikologis dari pekerjaannya. Masalah yang muncul kemudian adalah tubuh tidak dapat membangun kembali kemampuannya untuk menghadapi stres. Keadaan stres yang lama dengan intensitas yang cukup tinggi yang dimulai dengan kelelahan fisik, emosional dan mental dapat mengakibatkan pekerja mengalami burnout. Berdasarkan penjelasan tersebut seharusnya stres kerja bagi PLLU harus dihindari karena dapat berpengaruh kepada kesehatan diri maupun performa dalam bekerja. Pekerjaan PLLU membutuhkan fokus dan tenaga yang banyak seharusnya dapat diimbangi dengan sumber daya manusia yang banyak pula. Seorang PLLU dituntut dapat melakukan pekerjaanya secara multitasking, yaitu seorang PLLU harus mampu mengawasi sistem secara detail, membuat perhitungan dan mengambil keputusan secara cepat dan tepat. Bekerja secara multitasking tersebut membuat PLLU harus selalu fokus, sesuai peraturan yang ada PLLU berkerja dalam sistem shift. Sistem shift yang ada seringkali tidak berjalan dengan efektif karena kurangnya sumber daya manusia.

Idealnya seorang PLLU bekerja selama 7 jam dengan rincian 2 jam kerja dengan 45 menit istirahat perhari serta jadwal 3 hari kerja dan 2 hari libur Tak jarang seorang PLLU bekerja melebihi shift yang sudah diatur karena berbagai hal (Prokal, 2014). Hasil wawancara dengan $\mathrm{B}$, pria usia 36 tahun pernah bekerja melebihi shift-nya karena menggantikan posisi rekan kerja yang sedang sakit dan kekurangan sumber daya manusia. Temuan yang terjadi di lapangan, para PLLU bekerja selama 3 hari kerja dengan 1 hari libur dan sewaktu-waktu harus siap untuk bekerja. Waktu kerja selama 2 jam dan 45 menit istirahat bertujuan untuk menjaga fokus, terhindar dari kejenuhan dan kondisi fisik tetap prima. Hal tersebut menunjukkan bahwa waktu kerja dinilai belum sejalan dengan aturan yang ada. Waktu kerja seorang PLLU diatur oleh peraturan dengan tujuan menghindari adanya insiden fatal disebabkan oleh kelelahan yang dialami oleh PLLU.

Ketua umum Ikatan PLLU dalam suatu 
kesempatan mengutarakan fakta bahwa Indonesia pada 2016 sampai 2025 mendatang masih kekurangan 4000 PLLU. Jumlah yang ada saat ini dinilai belum memenuhi kebutuhan akan tenaga PLLU yang ada. Kekurangan tersebut akan bertambah seiring dengan akan pensiunnya PLLU yang segera purna tugas dalam waktu dekat (Helmi, 2016). Kekurangan PLLU tersebut membuat sistem shift tidak berjalan dengan efisien. PLLU banyak yang bekerja di luar batas jam kerja yang ditentukan. Bekerja di luar waktu yang ditentukan tersebut membuat para PLLU kehilangan waktu dengan keluarganya bahkan waktu untuk bersantai sejenak dari pekerjaan. PLLU dituntut professional, dalam hal ini professional adalah para PLLU bekerja sesuai dengan aturan dan proseduryang ada.

Menurut Bandura (Ghufron \& Risnawati, 2010) efikasi diri adalah keyakinan mengenai kemampuan dirinya dalam melakukan tugas atau tindakan yang diperlukan untuk mencapai hasil tertentu. Individu yang memiliki efikasi diri yang tinggi akan lebih memiliki semangat yang lebih baik dalam menjalankan suatu tugas tertentu dibandingkan dengan orang yang memiliki efikasi diri rendah. Sehingga seorang yang memiliki efikasi diri tinggi mampu mengembangkan sikap-sikap positif seperti rasa percaya diri dan komitmen yang tinggi dalam menjalankan peran dan fungsinya secara baik. PLLU idealnya memiliki efikasi diri yang tinggi. Efikasi diri yang tinggi akan memberikan manfaat bagi diri PLLU agar dapat bertugas dengan baik.

Kondisi yang ditemukan di lapangan efikasi diri yang dimiliki berbeda-beda tiap saatnya. Hasil wawancara dengan A, Perempuan usia 21 tahun seorang PLLU di Bandara mengatakan bahwa dia memiliki keyakinan akan kemampuan yang dimilikinya cukup baik, namun bila dipindahtugaskan di Bandara dengan kepadatan tinggi A merasa tidak yakin dan belum siap dengan beban pekerjaan yang akan dihadapi. Sedangkan wawancara dengan B, Pria berusia 36 tahun memiliki efikasi diri yang tinggi dan mengatakan bahwa jarang mengalami stres kerja. B merasa jarang merasakan stres kerja karena merasa yakin dengan kemampuan dan pengalamannya.

Berdasarkan permasalahan yang ada dapat dibayangkan betapa besarnya tanggung jawab dan beban kerja para PLLU tersebut. Tanggung jawab dan beban kerja yang berlebihan tersebut dapat membuat PLLU rentan mengalami stres kerja. Permasalahan yang dihadapi PLLU sendiri dapat membuat tingkat stres kerja cukup tinggi. Idealnya seorang PLLU memiliki stres kerja yang rendah serta diikuti dengan efikasi diri yang tinggi. Hal ini dikarenakan dapat berpengaruh dalam pekerjaanya. PLLU dituntut mampu bekerja dengan segala tekanan yang tidak terduga. Tekanan yang berasal dari pekerjaan seorang PLLU tidak jarang muncul rasa jenuh dan bosan. 
Jam kerja yang terkadang melebihi batas tenaga juga membuat keyakinan akan kemampuan diri seorang PLLU menjadi rendah karena kondisi fisik yang tidak prima dan hubungan diluar pekerjaannya. Berdasarkan latar belakang permasalahan, peneliti tertarik dan ingin membuktikan apakah ada hubungan antara efikasi diri dengan stres kerja pada PLLU.

\section{Metode}

\section{Subjek penelitian}

Subjek dalam penelitian ini adalah pengatur lalu lintas udara yang bekerja di bawah PERUM LPPNPI atau yang lebih dikenal AirNav Indonesia. Subjek penelitian merupakan pengatur lalu lintas udara yang masih aktif berdinas dan bukan pengatur lalu lintas yang saat ini mengisi jabatan manajerial. Subjek dalam penelitian ini bekerja pada divisi Aerodrome Control, Approach Control Unit, dan Area Control Centre. Subjek berjumlah 70 orang, terdiri dari 50 laki-laki dan 20 perempuan.

\section{Metode pengumpulan data}

Secara operasional, efikasi diri dan stres kerja adalah hasil yang diperoleh dari responden penelitian melalui self report setelah menjawab skala efikasi diri. Skala efikasi diri ini terdiri dari 18 aitem $(\alpha=0.888)$ mengungkap tiga aspek sebagai berikut: (a) generality, (b) generality dan (c) strength. Semakin tinggi hasil yang ditunjukkan pada skala efikasi diri menunjukkan bahwa semakin rendah tingkat efikasi diri, begitu pula sebaliknya, semakin tinggi hasil yang diperoleh dalam menjawab skala stres kerja menunjukkan semakin rendah efikasi diri yang dimiliki responden. Sedangkan tingkat stres kerja pada PLLU dapat diperoleh pada responden penelitian setelah menjawab skala stres kerja. Skala stres kerja ini terdiri dari 24 aitem $(\alpha=0.899)$ mengungkap tiga aspek sebagai berikut: (a) psikologis, (b) fisiologis dan (c) tingkah laku. Semakin rendah hasil yang ditunjukkan dalam skala stres kerja maka efikasi diri yang dimiliki PLLUcukup tinggi, sebaliknya jika dalam skala stres kerja menunjukkan hasil yang tinggi, maka dapat dikatakan efikasi rendah.

\section{Hasil}

Peneliti melakukan penelitian dengan tujuan untuk menguji hipotesis mengenai hubungan antara stres kerja dengan efikasi diri pada pengawas lalu lintas udara. Dari hasil penelitian dan analisis yang telah dilakukan oleh peneliti menunjukan bahwa hipotesis penelitian diterima. Hal tersebut dapa dilihat dari koefisien korelasi (r) sebesar -0.634 dengan $p=0,00$. Berdasarkan nilai koefisien korelasi dapat diartikan semakin tinggi efikasi diri pengawas lalu lintas udara maka semakin rendah stres kerjanya.

Hubungan antara stres kerja dan efikasi diri menunjukkan bawa efikasi memiliki 
pengaruh terhadap stres kerja para pemandu lalu lintas udara. Besarnya pengaruh efikasi terhadap stres kerja berdasarkan hasil analisis menunjukan bahwa nilai $r^{2}=0.402$ yang berarti efikasi diri memberikan sumbangsih sebesar $40 \%$ terhadap stres kerja pemandu lalu lintas udara. libur, jam kerja yang dapat berubah-ubah, keadaan darurat, keselamatan penerbangan, jenjang jarir, kejenuhan dan berbagai faktor lainnya yang tidak terungkap.

Tingkat stres kerja yang tinggi pada pemandu lalu lintas udara sejalan dengan pendapat Costa (2005) sebagian besar

Tabel 1. Hasil Uji Hipotesis

\begin{tabular}{ccc}
\hline Variabel & $r$ & $p$ \\
\hline Efikasi Diri ${ }^{*}$ Stres Kerja & -0.634 & 0.000 \\
\hline
\end{tabular}

\section{Pembahasan}

Idealnya seorang yang memiliki efikasi diri tinggi memiliki kemungkinan mengalami stres kerja yang rendah. Tingkat stres kerja pada pengawas lalu lintas udara disebabkan oleh sisa sumbangsih faktor yang tidak diungkap dalam penelitian ini. Untuk memperdalam data, peneliti melakukan wawancara terhadap beberapa pemandu lalu lintas udara. Berdasarkan hasil wawancara dapat diketahui bahwa umumnya para pemandu lalu lintas udara memiliki efikasi diri yang tinggi. Mereka merasa yakin dengan kemampuan yang ada dalam dirinya. Stres kerja yang tinggi juga sering muncul karena faktor dari luar yang tidak terduga. Kondisi kerja yang mengharuskan duduk dan melihat monitor dalam waktu panjang, kondisi cuaca yang dapat berubah sewaktu waktu, peralatan yang kurang memadai, tidak adanya waktu penelitian menunjukkan bahwa beban kerja yang berhubungan dengan para pengawas lalu lintas udara berkaitan dalam banyaknya pesawat yang dipandu, jumlah lalu lintas pesawat, durasi dan jenis komunikasi, jadwal kerja yang ketat dan kompleksitas masalah yang harus diselesaikan secara cepat. Perbandingan stres pada tiap pusat kontrol udara dapat direkam, terutama kaitannya dengan kepadatan lalu lintas udara. Zier (Lorne, 2005) mengungkapkan kurangnya atau lemahnya kontrol dalam pekerjaan bagi seorang pemandu lalu lintas udara dilaporkan sebagai penyebab stres kerja paling potensial, dimana pemandu lalu lintas udara adalah pekerjaan yang paling rentan menghadapi stres.

Hopkins (1995) berpendapat bahwa stres kerja yang terjadi dapat disebabkan oleh tugas, hubungan individu dengan kemampuan dan batasan yang dimiliki, 
keadaan pekerjaan dan iklim sosial. Penelitian yang Hopkins (1995) juga mengemukakan temuan pengaruh dari luar tempat kerja seperti pernikahan dan keadaan ekomoni dapat berpengaruh dalam pekerjaan. Beberapa studi kepribadian terhadap pemandu lalu lintas udara juga menemukan bahwa faktor kepribadian dapat mempengaruhi stres kerjanya. Secara umum seorang dengan kepribadian A akan lebih rentan mengalami stres kerja dibandingkan dengan orang dengan kepribadian B. Penelitian Janhua dkk ( 2014) menyebutkan bahwa seorang yang memiliki efikasi tinggi lebih mempunyai keyakinan terhadap kapabilitas, kompetensi dan kepercayaan diri yang tinggi dalam menangani kendala yang terjadi dalam pekerjaan mereka. Orang dengan tingkat efikasi diri tinggi lebih mempunyai pengaruh yang positif dalam mengurangi stres kerja mereka.

Iroegbi (2015) menjelaskan bahwa efikasi diri yang kuat berpengaruh pada prestasi dan kesejahteraan diri dalam berbagai cara. Individu yang memiliki rasa kompetensi akan menghadapi tantangan sebagai hal yang harus diselesaikan daripada menjadikannya sebagai bahaya yang harus dihindari. Tingginya efikasi diri membantu individu memiliki perasaan tenang dalam menghadapi tugas dan aktifitas yang susah. Sebaliknya individu dengan tingkat efikasi rendah memiliki perasaan hal yang dilakukannya akan lebih susah daripada kenyataanya. Keyakinan tersebut dapat menjadikan individu stres, depresi dan memiliki visi yang sempit tentang bagaimana cara menyelesaikan masalah. Penelitian Grau, Salanova dan Peiro (2001) mengemukakan bahwa secara umum penyebab stres akan memberikan dampak yang sangat kurang bagi seseorang yang memiliki persepsi positif pada dirinya dan lebih lagi bagi seorang yang mempunyai efikasi diri tinggi.

Penelitian yang dilakukan oleh Shoucksmith dan Burrough (Hopkins, 1995) pada pemandu lalu lintas udara menemukan bahwa penyebab stres paling tinggi bagi seorang pemandu lalu lintas udara adalah keterbatasan alat, kepadatan lalu lintas, keadaan lingkungan kerja, dan rasa takut menyebabkan kecelakaan fatal. Tingkat stres yang terjadi pada subjek dalam penelitian ini bisa juga disebabkan karena perbedaan kepadatan lalu lintas udara. Pemandu lalu lintas udara dengan tingkat penerbangan padat bisa lebih tinggi stres kerjanya dibanding bandara lainnya dengan tingkat kepadatan penerbangan yang rendah seperti Pattimura di Ambon, Juwata di Tarakan dan lainnya. Efikasi diri bagi seorang Pemandu lalu lintas udara adalah hal yang sangat penting. Hasil penelitian ini didukung oleh pendapat Luthans (2011) dimana seorang yang memiliki efikasi diri tinggi akan lebih 
mampu keluar dari tekanan, efikasi yang tinggi mampu membuat seorang memiliki ketahanan dalam menghadapi stres kerja. Seperti yang telah diuraikan di atas, penyebabpenyebab stres kerja bagi seorang pemandu lalu lintas sangat banyak. Luthans (2011) juga berpendapat bahwa seorang yang memiliki efikasi diri tinggi akan lebih merasa mampu dan percaya diri dalam mengerjakan sesuatu dalam suatu kondisi tertentu.

Secara keseluruhan, peneliti menyadari penelitian ini masih memiliki banyak kekurangan. Salah satu kelemahannya adalah peneliti tidak bisa turun langsung dalam mengambil data. Peneliti tidak bisa turun langsung dalam mengambil data karena lokasi kerja yang berada di dalam lingkungan bandara dan harus dijaga keamananya dari pihak yang tidak berkepentingan. Jumlah subjek juga dirasa kurang maksimal dikarenakan persebaran pemandu lalu lintas udara yang sangat tidak merata dimana di beberapa bandara jumlah pemandu lalu lintas udara hanya terdapat 5 orang dan di tempat lainya bisa di atas 30 bahkan lebih dari 100 . Sehingga peneliti tidak bisa secara langsung menjelaskan tentang mekanisme pengisian data agar mengisi dengan sebenarbenarnya. Alat ukur yang digunakan dalam penelitian ini dirasa kurang spesifik. Aitem yang digunakan sebaiknya dapat membahas secara spesifik pada pekerjaan Air Traffic Controller. Spesifiknya aitem dalam penelitian akan mampu untuk mengungkap secara rinci dan lebih dalam permasalahan yang ada di tempat penelitian.

\section{Simpulan}

Berdasarkan hasil analisis dan pembahasan, maka dapat disimpulkan bahwa efikasi diri mempengaruhi stres kerja pada Air Traffic Controller. Semakin tinggi efikasi diri maka akan semakin rendah stres kerja. Sebaliknya, apabila semakin rendah efikasi diri maka akan semakin tinggi stres kerjanya.

\section{Saran}

Berdasarkan hasil penelitian, ada beberapa saran yang dapat dikemukakan peneliti bagi pihak-pihak terkait dalam penelitian selanjutnya. Pertama saran bagi responden penelitian ini, yakni para pengatur lalu lintas udara agar mampu menemukan metode coping stress dan melatih diri agar mempunyai efikasi diri yang baik dan tepat bagi individu. Stres kerja yang dialami para pengatur lalu lintas udara seharusnya dapat dicegah dengan mengetahui penyebab-penyebab stres kerjanya.

Kedua, saran bagi instansi terkait dapat memahami permasalahan mengenai stres kerja pada pengatur lalu lintas udara serta mampu untuk menjaga para pengatur lalu lintas udara terhindar dari stres. Instansi terkait bisa 
memahami perbedaan stres ditiap bandaranya karena tingkat stres kerja Air Traffic Contoller antara bandara satu dengan lainnya bisa berbeda. Ketiga, saran bagi penelitian selanjutnya, diharapkan peneliti dapat menggali lebih dalam penyebab stres yang dialami oleh Air Traffic Contoller. Dalam pengambilan data peneliti idealnya bisa langsung turun bertemu dengan responden penelitian dan melakukan observasi dan wawancara lebih mendalam untuk mendapatkan data-data tambahan. Alat ukur yang dibuat atau digunakan dalam penelitian yang akan datang sebaiknya lebih spesifik. Alat ukur yang spesifik akan membantu peneliti untuk mendapatkan hasil yang lebih baik dan mendalam.

\section{Daftar Pustaka}

Bundesstelle fur Flugunfalluntersuchung. (2004). Airline Accident Statistics 2002. Diakses pada tanggal 10 November 2016, d a r i : h t t p : / / a vi a a t i o n safety.net/database/2002/0207010.htm.

Costa, G. (2005). Occupational Stress and Stress Prevention in Air Traffic Control. Geneva: International Labour Office.

Ghufron, M, N., \& Risnawati, R, S. (2010) TeoriTeori Psikologi. Yogyakarta: Ar-Ruzz Media.

Grau, R., Salanova, M., \& Peiro J,M. (2001). Moderator effects of Self-Efficacy on occupational Stress. Psychology in Spain. 5, 63-74. Diakses pada 15 November $2016, \quad d$ a r i : http://www.psychologyinspain.com/co ntent/reprints/2001/7.

Gunawan, R. (2015). Tragedi Garuda dan Teriakan Allah Akbar Pilot. Diakses pada t a n g g a l 20 M a r e t 2016 , dari:http://global.liputan6.com/read/2 326135/26-9-1997-tragedi-garuda-danteriakan-allahu-akbar-sang-pilot.

Helmi. (2016). Indonesia Butuh 4000 ATC Sampai 2025 Mendatang. Diakses pada tanggal 16 Januari 2017 , dari: http://beritatrans.com/2016/08/30/iat ca-indonesia-butuh-4-000-atc-sampai2025-mendatang.

Hopkins, D. (1995). Human Factor in Air Traffic Controller. United Kingdom: Advisory Group For Aerospace \& Development.

Iroegbi, M. (2015). Self efficacy and work performance : A theoretical framework of Albert Bandura's model, review of findings, impication and direction for future research. Psychology and Behavioral Science. 4(4), 170-173.

Janhua, Y., Chaudhary, C., \& Chauhan, M. (2014). Relationship between employees self efficacy belief and role stress: A study. $J$ Psychology. 5(2), $169-173$. doi:10.4304/jltr.2.5.1168-1174.

Kusumadewi., \& Galih. (2012). Ketika Penerbangan Kacau Akibat Radar Bandara Mati. Diakses pada tanggal 20 M a r e t $2016, \quad \mathrm{~d}$ a r i : http://fokus.news.viva.co.id/news/read /375598-ketika-penerbangan-kacau- 
akibat-radar-bandara-mati.

Lorne, S. (2005) Work Stress. Canada: Thomson Wadsworth.

Luthans, F. (2011). Organizational Behavior: An Evidence-Based approach. New York: The McGrow-Hill Companies, Inc.

Mangkunegara, A. (2009). Manajemen Sumber Daya Manusia. Bandung: Remaja Rosdakarya.

Pamudji, (2016). 2017 Maskapai Indonesia Terbangkan 1030 Pesawat. Diakses pada tanggal 5 Februari 2017, dari: http://www.teropongsenayan.com/370 70 - 2017 - maskapsi-di-indonesiaterbangkan-1030-pesawat.

Peraturan Kementrian Perhubungan Tentang Peraturan Keselamatan Penerbangan Sipil Bagian 170. (2009). Diakses pada tanggal 17 Februari 2017 , dari http://www.kemnhub.go.id.

Prokal. (2014). Idealnya Tiga Hari Kerja Dua Hari Libur Minim Personel Libur Jadi Sehari. Diakses pada tanggal 20 Maret $2016, \quad d$ a r i : http://m.kaltim.prokal.co/read/news/1 02600-idealnya-tigahari-kerjaduaharilibur-mjnim-personel-libur-jadi-sehari.

Taufik, M. (2013). Petugas ATC Gampang Stres, Wawancara Gatot Tri. Diakses pada tanggal 20 Maret 2016 , dari: https://www.merdeka.com/khas/petug as-atc-gampang-stres-wawncara-gatottria-a-2.html. 